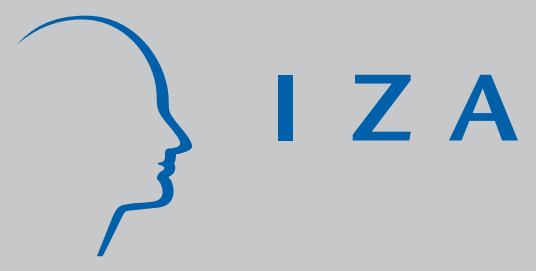

IZA DP No. 647

\title{
Envy and Compassion in Tournaments
}

\section{Christian Grund}

Dirk Sliwka

November 2002 


\title{
Envy and Compassion in Tournaments
}

\author{
Christian Grund \\ University of Bonn and IZA Bonn \\ Dirk Sliwka \\ University of Bonn \\ Discussion Paper No. 647 \\ November 2002
}

\author{
IZA \\ P.O. Box 7240 \\ D-53072 Bonn \\ Germany \\ Tel.: +49-228-3894-0 \\ Fax: +49-228-3894-210 \\ Email: iza@iza.org
}

This Discussion Paper is issued within the framework of IZA's research area Mobility and Flexibility of Labor. Any opinions expressed here are those of the author(s) and not those of the institute. Research disseminated by IZA may include views on policy, but the institute itself takes no institutional policy positions.

The Institute for the Study of Labor (IZA) in Bonn is a local and virtual international research center and a place of communication between science, politics and business. IZA is an independent, nonprofit limited liability company (Gesellschaft mit beschränkter Haftung) supported by the Deutsche Post AG. The center is associated with the University of Bonn and offers a stimulating research environment through its research networks, research support, and visitors and doctoral programs. IZA engages in (i) original and internationally competitive research in all fields of labor economics, (ii) development of policy concepts, and (iii) dissemination of research results and concepts to the interested public. The current research program deals with (1) mobility and flexibility of labor, (2) internationalization of labor markets, (3) welfare state and labor market, (4) labor markets in transition countries, (5) the future of labor, (6) evaluation of labor market policies and projects and (7) general labor economics.

IZA Discussion Papers often represent preliminary work and are circulated to encourage discussion. Citation of such a paper should account for its provisional character. A revised version may be available on the IZA website (www.iza.org) or directly from the author. 
IZA Discussion Paper No. 647

November 2002

\section{ABSTRACT}

\section{Envy and Compassion in Tournaments}

Many experiments indicate that most individuals are not purely motivated by material self interest, but also care about the well being of others. In this paper we examine tournaments among inequity averse agents, who dislike disadvantageous inequity (envy) and advantageous inequity (compassion). It turns out that inequity averse agents exert higher effort levels than purely self-interested agents for a given prize structure. Contrary to standard tournament theory first-best efforts can not be implemented when prizes are endogenous. Several extensions are studied like the case of spiteful agents, sabotage, asymmetric agents and an application on the choice between vertical and lateral promotions within firms.

JEL Classification: M51, M52, D23, D63

Keywords: tournaments, promotions, inequity aversion

Corresponding author:

Christian Grund

University of Bonn

BWL II

Adenauer Allee 24-42

53113 Bonn

Germany

Tel.: +49228739213

Fax: +49228739210

Email: christian.grund@uni-bonn.de 


\section{Introduction}

Tournaments are highly competitive situations, where agents compete for prizes as for instance employees for a promotion. Such situations of tournament competition have been analyzed analytically within many different frameworks since the seminal article of Lazear and Rosen (1981). ${ }^{1}$ A key aspect of the literature is that tournaments seem to be an effective incentive instrument in many situations. First of all, only ordinal information on the agent's performance is needed and even if performance signals are unverifiable to third parties, a tournament can induce incentives as the principal can credibly commit to pay out winner and loser prizes. Furthermore, tournament results are unaffected by common shocks that affect the performance of all participants.

However, it is important to note that tournaments necessarily create a high degree of income inequality even among initially identical agents. When agents are purely motivated by material self-interest, this does not pose a problem as the agents' well being and their incentives to exert effort is not affected by the ex-post inequality in payoffs. But many experiments indicate that a considerable number of individuals is not purely motivated by material self-interest, but cares about the well being of others. Loewenstein et al. (1989) for instance find strong evidence that people dislike inequitable payoff distributions and this has been confirmed in numerous other studies. ${ }^{2}$ As a general observation it can be stated, that a person's utility at a given individual income is lower, when other individuals either have higher or lower payoffs than the person itself. On the basis of experimental findings, Fehr

\footnotetext{
${ }^{1}$ Compare e.g. Nalebuff and Stiglitz (1983), O'Keefe et al. (1984), Bhattacharya and Guasch (1988) or Lazear (1989).

${ }^{2}$ Compare for instance Fehr and Schmidt (2002) for an overview.
} 
and Schmidt (1999) have developed a simple utility function to encompass inequity aversion as a form of social preferences. ${ }^{3}$ They show that many experimental findings that are puzzling when being analyzed with standard self-centered utility can be explained when inequity aversion is taken into account.

But if agents indeed do have such social preferences, the effectiveness of a tournament as an incentive instrument will be affected. On the one hand, the losers of a tournament may feel disadvantageous inequity, which can be characterized as envy in addition to having a lower material payoff than the winners. ${ }^{4}$ On the other hand, the winners enjoy the higher winner prize (for instance the promotion encompassing a wage increase) but may dislike advantageous inequity to some extent, which can be characterized as compassion. Note that it is not clear at the outset whether the motivation of an inequity averse agent in a tournament is higher or lower than that of a purely self-regarding agent. If an agent anticipates that he will sense envy when losing the tournament, this may rise his incentives to exert effort to prevent such a situation. But in contrast, the anticipation of compassion may lower the incentives, as winning the tournament becomes less attractive.

It is therefore necessary to study the effects of envy and compassion in a tournament formally. Applying the utility function developed by Fehr and Schmidt (1999), we analyze a very simple tournament model with two homogeneous agents. Inequity is specified as inequality in the approach of Fehr and Schmidt, which is suitable in a tournament situation, where the participants are situated in a symmetric decision environment. The utility function al-

\footnotetext{
${ }^{3} \mathrm{~A}$ similar approach has been taken by Bolton and Ockenfels (2000). See also Charness and Rabin (2002) for a recent detailed discussion of alternative utility representations of social preferences.

${ }^{4}$ For a different economic approach for the incorporation of envy compare Mui (1995).
} 
lows to separate very nicely the effects of advantageous and disadvantageous inequity aversion.

First, the outcome of a tournament among inequity averse agents is investigated for a given prize structure. Second, we investigate the optimal design of the tournament if the principal takes the inequity aversion of the agents into account. It turns out that for a given prize structure the equilibrium effort choice is increasing with the importance of envy and decreasing with that of compassion. If envy is a stronger feeling than compassion, which is typically confirmed by experimental studies, this leads to a positive overall effect of inequity aversion on equilibrium effort.

But this result is reversed if the agents' participation constraint is taken into account and the optimal tournament design is analyzed. On the one hand, the incentive effect caused by inequity aversion continues to be of importance. But on the other hand, the agents' inequity aversion leads to "inequity cost" that reduce their utility from taking part in the tournament. It turns out that only the participation effect matters for total welfare as the incentive effect is always neutralized by adapting the prize structure appropriately. Therefore, in contrast to a standard tournament model with risk neutral agents the optimal prize structure fails to implement first-best efforts when agents are inequity averse. It directly results that tournaments among agents with purely self-regarding preferences lead to a higher efficiency than tournaments among inequity averse agents.

There is one important point that has been neglected in the recent theoretical literature on inequity aversion, namely the question of the relevant reference group included in an agent's social preferences. As Loewenstein et al. (1989) point out, the extent of inequity aversion is affected by the social context. Therefore, it seems to be important to take this into account 
when analyzing the impact of social preferences on tournament outcomes in specific applications. In this paper, we consider the specific situation of a promotion tournament where agents compete for a job on a higher hierarchical level. A typical decision firms have to take in practice is whether the successor of some hierarchical superior should be chosen among the subordinates of this superior (vertical promotion) or from a different department (lateral promotion). We assume that inequity aversion is felt stronger if an individual compares his own well being with that of a close colleague than with someone less well known from a different branch of the organization as there is less social distance among direct colleagues. Then the described personnel policy choice should have an impact on the agents' utility and in turn on their incentives to exert effort in the promotion tournament. Therefore, we examine this application in closer detail in Subsection 5.4.

Only little work has been done so far that makes use of relative utility components in tournaments. Exceptions are the informal discussion by Stark (1990) and the model by Kräkel (2000) who introduces relative deprivation in tournaments. In those papers, individuals' behavior is only guided by the avoidance of relative deprivation which is related to disadvantageous inequity aversion but neither care for their direct material payoff nor consider the effects of advantageous inequity. Recent papers that have examined moral hazard problems with a single agent in view of inequity aversion are Englmaier and Wambach (2002) and Fehr et al. (2002).

The remainder of the paper proceeds as follows. In Section 2 we introduce our simple tournament model encompassing inequity averse preferences. The equilibrium effort choices for a tournament with a given prize structure are derived in Section 3. Afterwards, Section 4 deals with the optimal tournament prize structure, when the principal takes the participation constraint 
of the agents into account. For each case, the consequences of inequity aversion for the principal's profit are discussed. In Section 5 we analyze some extensions of the model. Spitefulness is discussed as an extreme case of an agent's preferences with interesting implications. Sabotage is introduced as a second possibility for the agents to improve their probability to win the tournament. Briefly we discuss the case of agents who are asymmetric with respect to their preferences for envy or compassion. Finally, the model is applied to the strategic decision of firms concerning their corporate promotion policy. Section 6 concludes.

\section{The Model}

We analyze a simple tournament model in which two agents $i=A, B$ compete for a prize which may for instance represent a promotion to a higher hierarchical level. Each of the two agents produces an individual output which accrues to the principal. Agent $i$ 's output is given by

$$
q_{i}=h\left(e_{i}\right)+\varepsilon_{i},
$$

where $e_{i}$ is the effort exerted by agent $i, h\left(e_{i}\right)$ a concave function and $\varepsilon_{i}$ a random component. The random components of both agents are independent and identically distributed. The cost of individual effort are $C\left(e_{i}\right)$ with $C^{\prime}\left(e_{i}\right)>0$ and $C^{\prime \prime}\left(e_{i}\right)>0$. The winner of the tournament is the agent who has produced the highest $q_{i}$. He gets the winner prize $w_{1}$ (for instance the wage on a higher level of the corporate hierarchy after a promotion) and the loser gets $w_{2}$ with $w_{2}<w_{1}$. For ease of notation we define the prize spread $\Delta w=w_{1}-w_{2}$.

As we discussed in the introduction we assume that the agents are inequity averse concerning the wage payments. To model this, we make use 
of the utility function developed by Fehr and Schmidt (1999). Agent i's $(i \in\{A, B\})$ utility is given by

$$
u_{i}=w_{i}-\alpha \max \left\{w_{j}-w_{i} ; 0\right\}-\beta \max \left\{w_{i}-w_{j} ; 0\right\}-C\left(e_{i}\right)
$$

where $w_{i}$ and $w_{j}$ are the wages of the agents. ${ }^{5}$ The agent's total utility is therefore the sum of his monetary income $w_{i}$ less some "inequity costs" and his costs of effort. On the one hand, the agents feel envy, i.e. they dislike disadvantageous inequality: If the agent earns one unit of money less than his colleague, his utility is reduced by $\alpha \geq 0$ units. On the other hand, the agents feel some form of compassion, i.e. they also dislike advantageous inequality to some extent characterized by the value of $\beta \geq 0$. Following Fehr and Schmidt as well as the empirical study by Loewenstein et al. (1989) we assume that the dislike of disadvantageous inequality is stronger than that of advantageous inequality, i.e. $\alpha>\beta$. Furthermore, we assume that $\beta \leq 1$, i.e. an agent is always better off if he receives more money and his colleague's income is held constant.

We can now easily compute the utility of the winner of the tournament. If agent $i$ is the winner, his utility is given by

$$
u_{i}^{W}=w_{1}-\beta \Delta w-C\left(e_{i}\right)=w_{2}+(1-\beta) \Delta w-C\left(e_{i}\right) .
$$

Hence, the utility gain from receiving the prize spread $\Delta w$ in addition to the lower prize $w_{2}$ is reduced by the "costs of compassion" $\beta \Delta w$. The corresponding utility if he loses is

$$
u_{i}^{L}=w_{2}-\alpha \Delta w-C\left(e_{i}\right) .
$$

\footnotetext{
${ }^{5}$ Note that we assume that the agents' preferences are not affected by the principal's income, as she does not belong to their reference group. Neither we assume that the principal has social preferences.
} 
The loser not only earns the lower prize $w_{2}$, but in addition he suffers from the "costs of envy" characterized by $\alpha \Delta w$.

\section{Incentives and Inequity Aversion}

In a first step, we analyze the agents' incentives in the tournament for a given prize structure $\left(w_{1}, w_{2}\right)$. Agent $i$ 's probability of winning the tournament is

$$
\operatorname{Pr}\left(q_{i}>q_{j}\right)=\operatorname{Pr}\left\{\varepsilon_{i}-\varepsilon_{j}>h\left(e_{j}\right)-h\left(e_{i}\right)\right\} .
$$

Let $G()$ be the distribution function of the random variable $\varepsilon_{i}-\varepsilon_{j}$ and $g()$ its density. Hence, $i$ 's winning probability is simply $1-G\left(h\left(e_{j}\right)-h\left(e_{i}\right)\right)=$ $G\left(h\left(e_{i}\right)-h\left(e_{j}\right)\right)$ and his expected utility in this situation is

$$
\begin{aligned}
E U_{i}\left(e_{i}\right)= & G\left(h\left(e_{i}\right)-h\left(e_{j}\right)\right)\left[w_{1}-\beta \Delta w-C\left(e_{i}\right)\right] \\
& +\left(1-G\left(h\left(e_{i}\right)-h\left(e_{j}\right)\right)\right)\left[w_{2}-\alpha \Delta w-C\left(e_{i}\right)\right] \\
= & w_{2}-\alpha \Delta w+G\left(h\left(e_{i}\right)-h\left(e_{j}\right)\right)[\Delta w(1-\beta+\alpha)]-C\left(e_{i}\right)(4)
\end{aligned}
$$

We now seek a Nash equilibrium of the effort choice game among both agents. Both are maximizing their expected utility with respect to $e_{i}$. The first order conditions are necessary for an equilibrium in pure strategies ${ }^{6}$ and yield

$$
\begin{aligned}
& g\left(h\left(e_{i}\right)-h\left(e_{j}\right)\right) h^{\prime}\left(e_{i}\right)[\Delta w(1-\beta+\alpha)]-C^{\prime}\left(e_{i}\right)=0, \\
& g\left(h\left(e_{j}\right)-h\left(e_{i}\right)\right) h^{\prime}\left(e_{j}\right)[\Delta w(1-\beta+\alpha)]-C^{\prime}\left(e_{j}\right)=0 .
\end{aligned}
$$

Note that $g(x)=g(-x)$ as the $\varepsilon_{i}$ are identically distributed. As in a standard tournament this directly implies that the equilibrium must be symmetric. ${ }^{7}$

\footnotetext{
${ }^{6}$ The existence of the pure-strategy equilibrium in tournament models is typically not automatically assured. See the discussion in Lazear and Rosen (1981), p. 845, fn. 2, or Nalebuff and Stiglitz (1983). Existence can be assured if $C(e)$ is "sufficiently convex", i.e. $\min _{e} C^{\prime \prime}\left(e_{i}\right)$ is sufficiently large such that the objective functions are concave.

${ }^{7}$ Note that $\frac{C^{\prime}(e)}{h^{\prime}(e)}$ is a monotonically increasing function of $e$.
} 
As usual, in tournament models the existence of such an equilibrium is ensured if the cost function is sufficiently convex. ${ }^{8}$ We can thus characterize equilibrium effort:

Proposition 1 In equilibrium, both agents choose identical effort levels $e_{1}=$ $e_{2}=e^{*}$ characterized by

$$
\Delta w(1-\beta+\alpha) g(0)=\frac{C^{\prime}\left(e^{*}\right)}{h^{\prime}\left(e^{*}\right)} .
$$

The equilibrium effort is increasing in the strength of envy $\alpha$ and decreasing in that of compassion $\beta$. A tournament among inequity averse agents leads to higher efforts than one among agents with purely self-regarding preferences.

As the right-hand side of (5) is increasing in $e$ the equilibrium effort is increasing in $\alpha$ and decreasing in $\beta$. Note that only the loser but not the winner of the tournament suffers from envy. The existence of envy thus enlarges the utility gap between the winner and the loser. But this of course induces higher incentives for the agents ex-ante to exert effort and thereby to raise the probability of winning the tournament. On the other hand, only the winner senses compassion. But a compassionate agent enjoys winning the tournament less and therefore compassion reduces incentives.

At first glance, it may seem intuitive that inequity averse agents should exert lower effort levels in a highly competitive situation as a tournament with very uneven outcomes. But the opposite is true. As for instance has been found by Loewenstein et al. (1989), disadvantageous inequality affects utility to a stronger extent than advantageous inequality. In the terms of our utility function we therefore assumed $\alpha>\beta$. Hence, the effect of envy

\footnotetext{
${ }^{8}$ Compare Lazear and Rosen (1981), p. 845, or Bhattacharya and Guasch (1988), p. 871.
} 
on incentives outweighs that of compassion. Our model therefore predicts larger equilibrium efforts when agents are inequity averse than with merely self-interested agents.

It is now of course of importance to analyze the impact of inequity aversion on optimal tournament design. In particular, it is interesting to see whether a principal organizing a tournament benefits from inequity aversion or whether she will be better off with purely self-interested agents.

It is instructive to consider a situation in which the prizes are fixed and given in advance and the agent's participation is guaranteed for instance because the wages are sufficiently high for exogenous reasons. In that case, we obtain the following straightforward corollary to Proposition 1:

Corollary 1 If the prize structure is fixed, the principal's profit is the higher the more envious the agents are and the lower the more they feel compassion. A tournament among inequity averse agents leads to higher profits than one among agents with purely self-regarding preferences.

As the principal's payoff is strictly increasing in the agents' effort and the prizes are given, she is better off when the agents exert more effort for a given prize structure.

\section{The Optimal Tournament Prize Structure}

So far the agents' decision to participate in the tournament has not been taken into account. If the principal can freely adapt the prize structure, this will of course be of importance. We assume that both agents' reservation utilities are given by $U_{0}$.

We will proceed by analyzing the optimal prize structure of a tournament 
with inequity averse agents and will again compare the results with those of a standard tournament with purely self-interested agents.

The principal's expected payoff is given by

$$
2 h\left(e^{*}\right)-2 w_{2}-\Delta w
$$

where $e^{*}$ is the equilibrium effort which according to (5) depends on the prize spread $\Delta w$. Now, she has to take into account that an agent $i$ 's expected utility from participating in the tournament is greater or equal than $U_{0}$, i.e.

$$
w_{2}+\frac{1}{2}(1-\beta-\alpha) \Delta w-C\left(e^{*}\right) \geq U_{0} .
$$

Note that the agents' expected utility when participating is lowered by envy and compassion: Envy reduces the attractiveness as an agent suffers to a larger extent from losing the tournament. But compassion does the same as winning the tournament is less attractive if the loser's payoff has an impact on the winner's utility. It is most plausible that $\alpha+\beta<1$, as otherwise increasing the winner prize without affecting the loser prize may make an agent worse off. Only for exceptional cases it might be possible that the disutility due to uneven outcomes outweighs the utility of a higher winner prize $(\alpha+\beta>1)$. We assume that $U_{0}$ is sufficiently small such that the principal will indeed always have an interest to hire both agents.

The principal maximizes her surplus given by (6) by taking into account the incentive condition (5) and the participation constraint (7). In equilibrium, the participation constraint will be binding. Otherwise the principal would be able to lower $w_{2}$ without affecting the incentive constraint. Hence, we can solve the binding constraint (7) for $w_{2}$ and obtain

$$
w_{2}=U_{0}-\frac{1}{2}(1-\beta-\alpha) \Delta w+C\left(e_{i}\right) .
$$


By substituting the result in the principal's objective function and rearranging terms we get that the principal maximizes the following expression

$$
\max _{\Delta w} \underbrace{2 h\left(e^{*}(\Delta w)\right)}_{\text {Revenue }}-\underbrace{2 C\left(e^{*}(\Delta w)\right)}_{\text {Cost of Effort }}-\underbrace{(\alpha+\beta) \Delta w}_{\text {"Inequity Costs" }}-\underbrace{2 U_{0}}_{\text {Agents' Opportunity Costs }}
$$

where $e^{*}(\Delta w)$ is the equilibrium effort for a given prize spread $\Delta w$ as defined by (5). The principal thus maximizes the total surplus from production $2(h(e)-C(e))$ reduced by $(\alpha+\beta) \Delta w$ and the agents' opportunity costs $2 U_{0}$. The latter term will be called the inequity costs of the tournament.

It is instructive to briefly consider the first-best solution obtained in the reference case where efforts are directly contractible. The principal would simply impose the effort levels maximizing the surplus from production. In that case no inequity costs arise. She would pay equal fixed wages to the agents that cover their costs of effort and meet the participation constraints. At the first-best effort levels the marginal costs of effort are therefore equal to the marginal return of production such that

$$
h^{\prime}\left(e^{F B}\right)=C^{\prime}\left(e^{F B}\right) .
$$

As we have seen, however, the implementation of a tournament automatically leads to an unequal treatment of both agents ex-post which encompasses in itself a utility loss that has to be taken into account when the tournament is designed. By solving (8) we analyze the impact of this utility loss:

Proposition 2 When agents are inequity averse the principal will implement effort levels $e^{S B}$ defined by

$$
h^{\prime}\left(e^{S B}\right)-\underbrace{\frac{(\alpha+\beta)}{2(1+\alpha-\beta) g(0)} \frac{C^{\prime \prime}\left(e^{S B}\right) h^{\prime}\left(e^{S B}\right)-C^{\prime}\left(e^{S B}\right) h^{\prime \prime}\left(e^{S B}\right)}{\left(h^{\prime}\left(e^{S B}\right)\right)^{2}}}_{>0}=C^{\prime}\left(e^{S B}\right) .
$$

These efforts are smaller than the efficient effort levels. 


\section{Proof:}

This can be seen in the simplest way by using $e$ instead of $\Delta w$ as the decision variable. Let $\Delta w(e)=e^{*-1}(e)$ be the prize spread that implements a given effort level $e$ in the tournament. From (5) we must therefore have that $\Delta w(e)=\frac{C^{\prime}(e)}{h^{\prime}(e)(1-\beta+\alpha) g(0)}$. We can reformulate (8) and obtain

$$
\max _{e} 2 h(e)-2 C(e)-2 U_{0}-(\alpha+\beta) \frac{C^{\prime}(e)}{h^{\prime}(e)(1+\alpha-\beta) g(0)}
$$

The first order condition directly yields (10). The second term of the lefthand side is strictly positive if $\alpha$ or $\beta>0$ as $C^{\prime \prime}(e) h^{\prime}(e)>0$ and $C^{\prime}(e) h^{\prime \prime}(e)<$ 0 for any value of $e$.

If agents have purely self-regarding preferences (i.e. $\alpha=\beta=0$ ) (10) and (9) coincide. The principal will implement the first-best effort. This is a standard result for symmetric tournaments (see Lazear and Rosen (1981)).

However, as Proposition 2 shows, this result no longer holds when agents are inequity averse: By comparing (10) with (9) it can be directly seen that the second-best effort levels implemented in the tournament are smaller than the first-best levels as the second term on the left-hand side of (10) is strictly positive if $\alpha$ or $\beta$ are positive. This is due to the inequity costs that arise in a tournament. As we have seen, implementing a high effort in a tournament necessarily comes along with an unequal treatment of both agents. The larger the prize spread, the higher is the effort level but also the greater is the inequality imposed. The principal has to compensate the agents for the utility loss triggered by the inequality. The higher $\Delta w$ the larger must be this compensation. Due to that effect it is too costly for the principal to implement the first-best effort. 
A direct corollary of this result is:

Corollary 2 When the principal can design the optimal tournament structure, a tournament among agents with purely self-regarding preferences leads to higher profits than one among inequity averse agents.

\section{Proof:}

With self-interested agents the principal will implement the first-best efforts. Hence, the surplus from production is maximized. With inequity aversion the surplus from production is lower and, in addition - although the agents get their reservation utility in both cases -, the sum of the wage payments to them is higher as they have to be compensated for the inequity. As can be seen from (8) his profit must therefore be smaller.

It is interesting to compare this result to that of Corollary 1 where we have shown that the principal is better off with competing inequity averse agents when the prize structure is given. In that case, the principal's interest lies in maximizing efforts for a given prize spread. As we have seen, inequity averse agents exert higher efforts in a given tournament than self-interested agents. Hence, there is an incentive effect of inequity aversion which seems to work in favour of the principal. Now, we also took into account the effect of inequity aversion on the attractiveness of taking part in a tournament. As we have shown, inequity averse agents dislike the inherent inequality of the tournament and have to be compensated for this. This participation effect works into the opposite direction and makes the principal worse off when agents are inequity averse.

To understand why the latter is dominant it is important to note that the incentive effect vanishes entirely when the prize structure can be freely 
adapted. The principal can always set a $\Delta w$ of arbitrary size and implement any effort level she likes as she can always adapt the loser prize $w_{2}$ such that she never leaves any rent to the agents. But the inequity costs remain in any tournament.

\section{Extensions}

Based on our general model we can derive additional results with extensions of the framework. In particular, we focus on four simple extensions: First, we consider the extreme case of agents with preferences representing spitefulness, second, we introduce the possibility of sabotage as a different way for the agents to influence the tournament outcome. Third, we look at agents who are heterogeneous in terms of varying inequity attitudes and fourth, we apply our model to a firm's decision on its promotion policy.

\subsection{Spitefulness}

In our analysis we have assumed so far that agents sense compassion, when they are better off than their respective colleagues, which has been represented by assuming positive values of $\beta$. But as pointed out by Loewenstein et al. (1989) for instance, in some situations the opposite form of social preferences can be observed: spitefulness. An agent is spiteful, if he derives pleasure from being better off than his colleague which can easily be introduced in the model by simply assuming that $\beta<0$.

By inspecting Equation (5) in Proposition 1 it can be directly seen that spiteful agents exert even higher efforts for a given prize structure. Like before, they suffer from envy when losing the tournament, which reduces the utility in case of being second. But those agents also receive the additional 
pleasure of being better off than the loser when winning the tournament which increases the utility in case of being first. Hence, the utility spread generated by the prize spread $\Delta w$ is higher when agents are spiteful, which in turn generates additional incentives. For a given prize structure the principal is therefore better off when spiteful agents compete in a tournament.

But it is interesting to consider also the participation effect in view of the spitefulness of agents. As long as $\alpha>|\beta|$ the result of Proposition 2 continues to hold that the principal implements less than first-best effort with a tournament when the agents are inequity averse. If $\alpha=|\beta|$ then the first-best effort is attained as can be seen form equation (10). However, when spitefulness is stronger than envy, i.e. $\alpha<|\beta|$, it can be directly seen that the principal will implement even more effort than in the first-best solution in that case. The reason for this result is that the 'joy' of being better off than the opponent for the winner outweighs the costs of envy borne by the loser. The principal can use this and reduce his overall payment to the agents by increasing the prize spread even though this leads to inefficiently high effort levels. She will do this only to some extent as effort costs are convex and the gain from exploiting the agents' extreme spitefulness is only linearly increasing.

\subsection{Sabotage}

It has been stressed by Lazear (1989) that one drawback of tournaments is that agents may have an incentive to increase their own chances of winning by sabotaging their opponents. We now briefly consider the effect of inequity aversion on the agents' incentives to exert such counterproductive effort.

Both agents now have a second possibility to improve their winning probabilities in the tournament next to the effort choice $e_{i}$. Similar to Lazear we 
assume that agent $i$ can choose a sabotage effort $s_{i}$ against his opponent in order to reduce the opponent's output. Hence, an agent $i$ 's output $q_{i}$ is influenced by his own effort level $e_{i}$, the amount of sabotage of his opponent $s_{j}$ and again by the random component $\varepsilon_{i}$ :

$$
q_{i}=h_{e}\left(e_{i}\right)-h_{s}\left(s_{j}\right)+\varepsilon_{i}
$$

where $\partial h_{s} / \partial s>0$ and $\partial^{2} h_{s} / \partial s^{2}<0$. Agent $i$ 's effort cost now depend on the choice of $e_{i}$ and $s_{i}$ and is assumed to be convex in both terms $C_{e}\left(e_{i}\right)$ and $C_{s}\left(s_{i}\right)$. Thus, the utility of the winner $\left(u_{i}^{W}\right)$ and the loser $\left(u_{i}^{L}\right)$ of the tournament is simply:

$$
\begin{aligned}
u_{i}^{W} & =w_{1}-\beta \Delta w-C_{e}\left(e_{i}\right)-C_{s}\left(s_{i}\right) \\
u_{i}^{L} & =w_{2}-\alpha \Delta w-C_{e}\left(e_{i}\right)-C_{s}\left(s_{i}\right) .
\end{aligned}
$$

As before, we can compute the expected utility of agent $i$ :

$$
\begin{gathered}
E U_{i}=w_{2}-\alpha \Delta w+G\left(h_{e}\left(e_{i}\right)-h_{s}\left(s_{j}\right)-h_{e}\left(e_{j}\right)+h_{s}\left(s_{i}\right)\right)[\Delta w(1-\beta+\alpha)] \\
-C_{e}\left(e_{i}\right)-C_{s}\left(s_{i}\right)
\end{gathered}
$$

We can again compute the first order conditions and obtain that in a pure strategy Nash equilibrium both agents choose identical effort levels $e_{1}=$ $e_{2}=e^{*}$ and now also identical levels of sabotage $s_{1}=s_{2}=s^{*}$, which are determined by:

$$
\begin{aligned}
& \Delta w(1-\beta+\alpha) \cdot g(0)=\frac{C_{e}^{\prime}\left(e^{*}\right)}{h_{e}^{\prime}\left(e^{*}\right)} \\
& \Delta w(1-\beta+\alpha) \cdot g(0)=\frac{C_{s}^{\prime}\left(s^{*}\right)}{h_{s}^{\prime}\left(s^{*}\right)} .
\end{aligned}
$$

The first condition (12) corresponds to condition (5) in Proposition 1 before. As it is already known from Lazear (1989) increasing the wage spread increases the productive as well as the counterproductive effort. Furthermore, 
the equilibrium level of sabotage is increasing in the strength of envy and decreasing in that of compassion. Therefore, if sabotage is possible for a fixed prize structure not only the productive effort of inequity averse agents but also the counterproductive sabotage effort is higher compared to the case of purely self interested agents. This result is in line with experimental evidence by Harbring and Irlenbusch (2002). They find that the average effort and sobatage choice exceeds the equilibrium level predicted by standard tournament theory with purely self interested agents.

Analogously to the case of self interested agents analyzed in Lazear (1989) the optimal prize spread will be smaller, when the possibility of sabotage exists. But in consequence of a decreasing prize spread, the agents lower their productive effort as well.

\subsection{Asymmetric Agents}

Until now we have assumed that the agents are homogeneous with regard to their feelings of envy and compassion. It may, however, seem to be interesting to derive the equilibrium effort levels in the case of asymmetric agents. We now concentrate on asymmetric agents with respect to the strength of envious and compassionate preferences. ${ }^{9}$ Hence, we now allow for different values of $\alpha$ and $\beta$ between the agents. Again the agents are maximizing their expected utility with respect to $e$ :

$$
\begin{aligned}
& \max _{e_{i}} w_{2}-\alpha_{i} \Delta w+G\left(h\left(e_{i}\right)-h\left(e_{j}\right)\right)\left[\Delta w\left(1-\beta_{i}+\alpha_{i}\right)\right]-C\left(e_{i}\right) \\
& \max _{e_{j}} w_{2}-\alpha_{j} \Delta w+G\left(h\left(e_{j}\right)-h\left(e_{i}\right)\right)\left[\Delta w\left(1-\beta_{j}+\alpha_{j}\right)\right]-C\left(e_{j}\right)
\end{aligned}
$$

\footnotetext{
${ }^{9}$ See O'Keefe et al. (1984) for the analysis of asymmetric agents in tournaments with regard to their ability. One of their important results, namely that the agent with the higher ability chooses a higher effort level, can easily be replicated with our approach by introducing different functions of $h(e)$.
} 
The first order conditions yield

$$
\begin{aligned}
g\left(h\left(e_{i}\right)-h\left(e_{j}\right)\right) h^{\prime}\left(e_{i}\right)\left[\Delta w\left(1-\beta_{i}+\alpha_{i}\right)\right]-C^{\prime}\left(e_{i}\right) & =0 \\
g\left(h\left(e_{j}\right)-h\left(e_{i}\right)\right) h^{\prime}\left(e_{j}\right)\left[\Delta w\left(1-\beta_{j}+\alpha_{j}\right)\right]-C^{\prime}\left(e_{j}\right) & =0
\end{aligned}
$$

and, as $g\left(h\left(e_{i}\right)-h\left(e_{j}\right)\right)=g\left(h\left(e_{j}\right)-h\left(e_{i}\right)\right)$, we get that in equilibrium the following must hold:

$$
\frac{C^{\prime}\left(e_{j}^{*}\right) / h^{\prime}\left(e_{j}^{*}\right)}{\left(1-\beta_{j}+\alpha_{j}\right)}=\frac{C^{\prime}\left(e_{i}^{*}\right) / h^{\prime}\left(e_{i}^{*}\right)}{\left(1-\beta_{i}+\alpha_{i}\right)}
$$

We will therefore typically have asymmetric equilibria when the agents differ in the extent of inequity aversion. For identical levels of $\beta$ the more envious agent (the agent with the higher level of $\alpha$ ) will choose the higher effort level since $C^{\prime}(e) / h^{\prime}(e)$ is increasing in $e$. On the other hand, the more compassionate agent (with the higher level of $\beta$ ) will choose the lower effort level for an equal value of $\alpha$. Hence, just like in the result of our initial model with homogeneous agents, effort is increasing in the level of envy and decreasing in the level of compassion as the marginal benefits of the agents rise (decrease) with increasing envy (compassion).

\subsection{Vertical versus Lateral Promotions}

The former considerations are now applied to a specific question of personnel policy. The management of a firm has to decide about the general promotion policy. In principle, there are two extreme possibilities to organize promotions within a corporate hierarchy. ${ }^{10}$ First, there might be only vertical promotions in the sense that the promoted agent becomes the superior of the group (department, branch,...) he formerly worked in. Second, lateral promotions may take place in the form that a promoted employee gets a position

\footnotetext{
${ }^{10}$ We abstract from the option of external recruitments. See Chan (1996) for the analysis of this question.
} 
in a different part of the firm or may become the superior of a neighboring group. For simplicity we think of a firm with two groups $A$ (with the agents $i$ and $j$ ) and $B$ (with the agents $k$ and $l$ ), where the agents in each group compete for a promotion to a managing position (see Figure 1). The idea is that only the ordinal rank of an agent within his group is observable and, hence, only one agent from each group can be promoted. ${ }^{11}$

A key assumption we make is that envy and compassion are stronger when promotions are vertical. In this case the winner of the promotion tournament becomes the superior of the corresponding loser which is his former colleague and both are faced with the result of the tournament permanently. In the case of lateral promotions the winner is separated from the loser subsequent to the tournament (i.e. the winner of the tournament of group $A$ becomes the manager of group $B$ ). Hence, the winner will sense less compassion and the loser will feel less envious than in the vertical promotion case. Neither winner nor loser do face their former colleagues any more. For simplicity and analytical clarity we assume that envy and compassion do not matter at all in the case of lateral promotions. ${ }^{12}$

What kind of promotion policy should the management choose? In order to approach this question we apply our simple model from Section 2 to the quoted problem. Let $\tau$ be the probability of a vertical promotion in a firm so that with probability $1-\tau$ winners of promotion tournaments are promoted

\footnotetext{
${ }^{11}$ Note that this of couse has some drawbacks. Since tournaments often extend over a longer time period, intermediate information may weaken incentives if agents compete within one department (see McLaughlin (1988), p. 249 or Prendergast and Topel (1993) , p. 362). This may not be the case if agents compete across departments.

${ }^{12}$ Qualitatively, our results hold if envy and compassion are simply weaker with lateral promotions.
} 

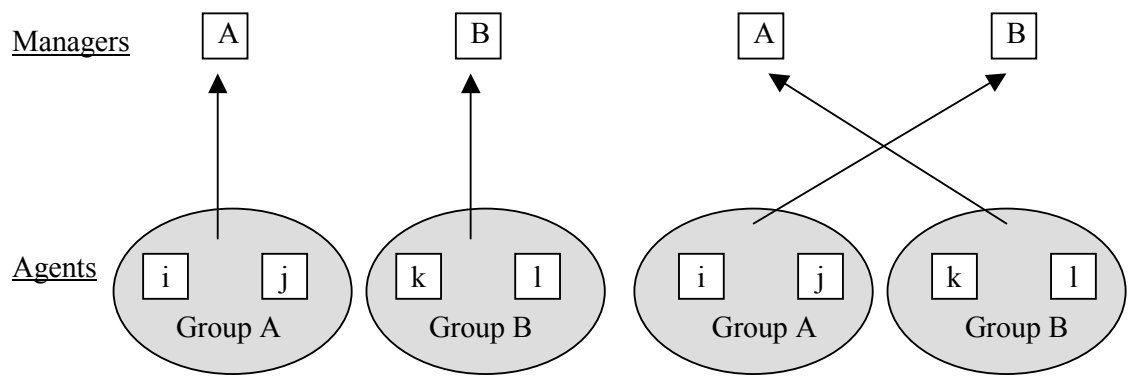

Figure 1: Vertical and Lateral Promotions

laterally. Envy and compassion do only matter in vertical promotions. This lead to the expected utility of agent $i$ of

$$
E U_{i}\left(e_{i}\right)=w_{2}-\tau \alpha \Delta w+G\left(h\left(e_{i}\right)-h\left(e_{j}\right)\right)[\Delta w(1-\tau \beta+\tau \alpha)]-C\left(e_{i}\right)
$$

Analogously to (5) the optimal effort choices of the agents can be computed by maximizing this expression. They are determined by:

$$
g(0) \Delta w(1+\tau(\alpha-\beta))=\frac{C^{\prime}\left(e^{*}\right)}{h^{\prime}\left(e^{*}\right)} .
$$

Since $\alpha>\beta, e^{*}$ is increasing in $\tau$. Hence, effort is maximized with $\tau=1$. For a given prize structure vertical promotions should be preferred to the lateral promotion policy. As in Proposition 1 the (positive) effect of envy outweighs the (negative) effect of compassion. The effort is higher as the agents work harder to prevent the situation of becoming the subordinate of a former direct colleague.

Analogously, it is very easy to see that the implementation of lateral promotions become favorable, when the principal takes the participation constraint into account and therefore the effect of the promotion policy on the agents's utility of working in the firm. In this case, inequity costs can be economized, which lead to higher profits for the principal. As people dislike 
being either a subordinate or a superior of a former colleague, the principal can raise the utility (i.e., the job satisfaction) of his employees when committing to a lateral promotion policy.

This result holds without further restrictions as long as there are no large differences in the required human capital for the managing positions $A$ and $B$. But it might be possible that the agents of group $A$ acquire some knowledge or ability by on-the-job training, which is important especially for the managing position $A$. This group-specific human capital cannot be accumulated by the agents in group $B$, who are the candidates for the managing position $A$, if the principal insists on lateral promotions. If the costs of necessary additional training in the case of lateral promotions outweigh the economized inequity costs, vertical promotions may still be the best policy.

\section{Conclusion}

In this paper, we have analyzed the effects of inequity aversion on incentives in tournaments. We defined negative inequity aversion as envy and positive inequity aversion as compassion. It has been shown that inequity averse agents exert higher effort levels than purely self-interested agents for a given prize structure but that first-best efforts are no longer implemented when

prizes are endogenous. In that case, tournaments inherently create inequity costs as they create an outcome with asymmetric payoffs even if initially agents are identical.

Several applications have been studied. First of all, if agents are spiteful, defined as negative compassion, then it might be optimal for the principal to choose prize spreads that lead to effort levels which are larger than firstbest efforts in the extreme case where spitefulness exceeds envy. Second, the 
effect of social preferences on the incentives to sabotage colleagues has been briefly investigated: Whereas envious agents tend to exert higher levels of counterproductive effort compassion reduces the danger of sabotage.

Finally, the question has been studied whether firms should choose lateral or vertical promotion policies. It has been pointed out that vertical promotions lead to higher efforts with a given wage structure. But lateral promotions might be beneficial when the agents' participation decision is taken into account as they economize on "inequity costs". These costs arise when former colleagues from the same department find themselves in a situation of one being the superior of the other. 


\section{References}

Bhattacharya, S. and Guasch, J. L. (1988): Heterogeneity, Tournaments, and Hierarchies. Journal of Political Economy, 96, pp. 867-881.

Bolton, G. and Ockenfels, A. (2000): ERC - A Theory of Equity, Reciprocity and Competition. American Economic Review, 90, pp. 166-193.

Chan, W. M. (1996): External Recruitment versus Internal Promotion. Journal of Labor Economics, 14, pp. 555-70.

Charness, G. and Rabin, M. (2002): Understanding Social Preferences with Simple Tests. Quarterly Journal of Economics, 117, pp. 817-869.

Englmaier, F. and Wambach, A. (2002): Contracts and Inequity Aversion. Mimeo, University of Munich.

Fehr, E., Klein, A. and Schmidt, K. (2002): Fairness, Incentives, and Contractual Incompleteness. Mimeo, University of Munich.

Fehr, E. and Schmidt, K. (1999): A Theory of Fairness, Competition, and Cooperation. Quarterly Journal of Economics, 114, pp. 817-868.

Fehr, E. and Schmidt, K. (2002): Theories of Fairness and Reciprocity Evidence and Economic Applications. In: Dewatripont, M., Hansen, L. and Turnovsky, St. (Ed.) Advances in Economics and Econometrics - 8th World Congress.

Harbring, C. and Irlenbusch, B. (2002): Anreize zu produktiven und destruktiven Anstrengungen durch relative Entlohnung. mimeo, University of Bonn. 
Kräkel, M. (2000): Relative Deprivation in Rank-Order Tournaments. Labour Economics, 7, pp. 385-407.

Lazear, E. P. (1989): Pay Equality and Industrial Politics. Journal of Political Economy, 97, pp. 561-80.

Lazear, E. P. and Rosen, S. (1981): Rank-Order Tournaments as Optimum Labor Contracts. Journal of Political Economy, 89, pp. 841-864.

Loewenstein, G., Thompson, L. and Bazerman, M. (1989): Social Utility and Decision Making in Interpersonal Contexts. Journal of Personality and Social Psychology, 57, pp. 426-441.

McLaughlin, K. (1988): Aspects of Tournament Models: A Survey. Research in Labor Economics, 9, pp. 225-56.

Mui, V.-L. (1995): The Economics of Envy. Journal of Economic Behavior and Organizations, 26, pp. 311-36.

Nalebuff, B.J. and Stiglitz, J.E. (1983): Prizes and Incentives: Towards a General Theory of Compensation and Competition. Bell Journal of Economics, 3, pp. 21-43.

O'Keefe, M., Viscusi, W. and Zeckhauser, R. (1984): Economic Contests: Comparative Reward Schemes. Journal of Labor Economics, 2, pp. 27-56.

Prendergast, C. J. and Topel, R. H. (1993): Discretion and Bias in Performance Evaluation. European Economic Review, 37, pp. 355-65.

Stark, O. (1990): A Relative Deprivation Approach to Performance Incentives in Career Games and Other Contests. Kyklos, 43, pp. 211-227. 


\section{IZA Discussion Papers}

\begin{tabular}{|c|c|c|c|c|}
\hline No. & Author(s) & Title & Area & Date \\
\hline 631 & $\begin{array}{l}\text { H. O. Duleep } \\
\text { M. Regets }\end{array}$ & $\begin{array}{l}\text { The Elusive Concept of Immigrant Quality: } \\
\text { Evidence from 1970-1990 }\end{array}$ & 1 & $11 / 02$ \\
\hline 632 & $\begin{array}{l}\text { B. Cockx } \\
\text { M. Dejemeppe }\end{array}$ & $\begin{array}{l}\text { Duration Dependence in the Exit Rate out of } \\
\text { Unemployment in Belgium. Is It True or } \\
\text { Spurious? }\end{array}$ & 2 & $11 / 02$ \\
\hline 633 & A. D. Kugler & Employee Referrals and Efficiency Wages & 5 & $11 / 02$ \\
\hline 634 & $\begin{array}{l}\text { A. D. Kugler } \\
\text { R. M. Sauer }\end{array}$ & $\begin{array}{l}\text { Doctors Without Borders: The Returns to an } \\
\text { Occupational License for Soviet Immigrant } \\
\text { Physicians in Israel }\end{array}$ & 1 & $11 / 02$ \\
\hline 635 & $\begin{array}{l}\text { M. Karanassou } \\
\text { D. J. Snower }\end{array}$ & An Anatomy of the Phillips Curve & 3 & $11 / 02$ \\
\hline 636 & $\begin{array}{l}\text { M. Karanassou } \\
\text { H. Sala } \\
\text { D. J. Snower }\end{array}$ & $\begin{array}{l}\text { A Reappraisal of the Inflation-Unemployment } \\
\text { Tradeoff }\end{array}$ & 3 & $11 / 02$ \\
\hline 637 & $\begin{array}{l}\text { H. Bonin } \\
\text { W. Kempe } \\
\text { H. Schneider }\end{array}$ & $\begin{array}{l}\text { Household Labor Supply Effects of Low-Wage } \\
\text { Subsidies in Germany }\end{array}$ & 3 & $11 / 02$ \\
\hline 638 & $\begin{array}{l}\text { L. McLeod } \\
\text { M. R. Veall }\end{array}$ & $\begin{array}{l}\text { The Dynamics of Food Deprivation and Overall } \\
\text { Health: Evidence from the Canadian National } \\
\text { Population Health Survey }\end{array}$ & 2 & $11 / 02$ \\
\hline 639 & G. Saint-Paul & Are Intellectual Property Rights Unfair? & 3 & $11 / 02$ \\
\hline 640 & $\begin{array}{l}\text { J. Hartog } \\
\text { N. Jonker } \\
\text { H. van Ophem }\end{array}$ & $\begin{array}{l}\text { Dual Track or Academic Route for Auditors: } \\
\text { Does It Matter? }\end{array}$ & 6 & $11 / 02$ \\
\hline 641 & $\begin{array}{l}\text { J. Hartog } \\
\text { L. Diaz Serrano }\end{array}$ & $\begin{array}{l}\text { Earning Risk and Demand for Higher Education: } \\
\text { A Cross-Section Test for Spain }\end{array}$ & 2 & $11 / 02$ \\
\hline 642 & $\begin{array}{l}\text { J. Hartog } \\
\text { A. Zorlu }\end{array}$ & $\begin{array}{l}\text { The Effect of Immigration on Wages in Three } \\
\text { European Countries }\end{array}$ & 2 & $11 / 02$ \\
\hline 643 & $\begin{array}{l}\text { A. Björklund } \\
\text { M. Sundström }\end{array}$ & $\begin{array}{l}\text { Parental Separation and Children's Educational } \\
\text { Attainment: A Siblings Approach }\end{array}$ & 6 & $11 / 02$ \\
\hline 644 & $\begin{array}{l}\text { J. D. Brown } \\
\text { J. S. Earle }\end{array}$ & $\begin{array}{l}\text { Job Reallocation and Productivity Growth Under } \\
\text { Alternative Economic Systems and Policies: } \\
\text { Evidence from the Soviet Transition }\end{array}$ & 4 & $11 / 02$ \\
\hline 645 & $\begin{array}{l}\text { M. Karanassou } \\
\text { H. Sala } \\
\text { D. J. Snower }\end{array}$ & $\begin{array}{l}\text { Long-Run Inflation-Unemployment Dynamics: } \\
\text { The Spanish Phillips Curve and Economic Policy }\end{array}$ & 3 & $11 / 02$ \\
\hline 646 & $\begin{array}{l}\text { L. Graham } \\
\text { D. Snower }\end{array}$ & The Return of the Long-Run Phillips Curve & 3 & $11 / 02$ \\
\hline 647 & $\begin{array}{l}\text { C. Grund } \\
\text { D. Sliwka }\end{array}$ & Envy and Compassion in Tournaments & 1 & $11 / 02$ \\
\hline
\end{tabular}

An updated list of IZA Discussion Papers is available on the center's homepage www.iza.org. 